\title{
EDITORIAL
}

\section{Building a Pipeline to Equity}

\author{
Amanda Kost, MD, MEd \\ Department of Family Medicine, University of Washington, Seattle, Washington
}

Ann Fam Med 2018;16:288-289. https://doi.org/10.1370/afm.2276.

$\mathrm{T}$ The US health care system is full of broken promises. Education is supposed to be the great equalizer, yet for many students a medical education remains out of reach. Over 10 years ago the Association of American Medical Colleges looked at the economic diversity of medical students by parental income and found that an astounding $50 \%$ or more come from families in the top $20 \%$ of income. ${ }^{1}$ Those with parents in the bottom $20 \%$ made up less than $5 \%$ of future physicians. Although patients come from all economic levels, their physicians do not reflect this. Medicine continues to have an over-representation of white people and a corresponding under-representation of people who identify as African American, Native American, or Latino/a. ${ }^{2}$ These disparities in race and class have real impacts, as implicit bias can influence the care provided and patients, understandably, would like to be cared for by someone similar to themselves. ${ }^{3}$ Furthermore, students from disadvantaged backgrounds are more likely to end up caring for patients who also face disadvantage. ${ }^{4}$

Our current medical school output largely reflects a group of people privileged by both race and class. At the same time, despite all evidence that suggests a robust primary care workforce can improve the health of the public, less than $10 \%$ of US medical graduates enter family medicine residencies each year. ${ }^{5,6}$ When finished with their medical education, practicing physicians do not distribute themselves uniformly, with persistent workforce shortages in rural areas and at community health centers that serve impoverished and disadvantaged populations. ${ }^{78}$ Taken together, medical schools are largely inaccessible to all but a privileged few and produce a workforce that does meet the needs of patients, either by specialty or demographics.

Conflicts of interest: author reports none.

\section{CORRESPONDING AUTHOR}

Amanda Kost, MD, MEd

Health Sciences Center (E-304)

Box 356390

Seattle, WA 98195

akost@uw.edu
But what if there was one thing that could help change all of this? There is, and you probably have one in your neighborhood. It's called community college and it has the potential to help address the failings of medical schools currently. Talamantes and colleagues studied medical student community college exposure, demographics, and specialty choice and report that students with community college experience are more likely to come from underrepresented backgrounds and more likely to enter family medicine, compared with students without such experience..$^{9}$ In this way, community college represents an important yet undervalued asset to promote health equity for our patients through a robust and diverse primary care workforce and a means of promoting educational equity for the vast majority of students whose parents are not in the top quintile of income.

The pathway from community college to medical school is complex and ill-defined. Students can attend community college during high school, before or after obtaining a bachelor's degree. Some students use community college to augment their education while others use it as a stepping stone on the way to other educational endeavors. The authors specifically looked at these different paths to see if they constituted different populations of students. What they found is that they probably do. Nevertheless, after adjusting for known demographic cofounders, attending community college for any reason made it more likely for a student to enter family medicine, and to be from a group underrepresented in medicine. Perhaps neither of these findings come as much of a surprise. Of all higher educational institutions, community college might be the easiest to access, regardless of economic or social background. ${ }^{10}$

How should medical schools and family medicine departments respond to these findings given the dual context of who currently has access to medical education and the workforce needs of the country? These findings suggest that we take a hard look at how we think about medical school admissions and the value we assign community college education versus a traditional 4-year degree. ${ }^{11}$ Community college should not be a barrier for medical school admission. On the con- 
trary, it should be valued for not only the education it provides, the spaces it builds and offers disadvantaged students, but also for the pipeline it creates for those who otherwise could not apply to medical school.

Furthermore, medical schools and family medicine departments should consider their role of reaching further back into the pipeline to students currently enrolled in community college. They should capitalize on existing collaborations and build new ones to strengthen the pipeline and lay down a clear path between educational institutions. As Talamantes points out, some states are already exploring such collaborations. This study looked only at specialty outcome; a further area of research includes examining if medical students with community college experience are more likely to enter residencies that focus on preparing them for practice in medically underserved areas. Investigating eventual practice location outcomes will also be critical to strengthening the argument that students from community college end up serving the patients most in need. As family doctors, we need to engage in this capacity building and research work for our patients, so the next of generation of physicians better reflects their diversity, and also for ourselves, to ensure that there are people who care for our patients when we are gone. Finally, we need to do it for our students, with the aim of improving educational equity in this country. Every patient deserves a family physician and every student deserves an opportunity to become that family physician.

To read or post commentaries in response to this article, see it online at http://www.AnnFamMed.org/content/16/4/288.

Submitted May 30, 2018; accepted June 8, 2018.
Acknowledgments: I thank Bill Phillips, Toby Keys, and Genya Shimkin for their invaluable comments on this piece.

\section{References}

1. Jolly P. AAMC Analysis In Brief. Washington, DC: Association of American Medical Colleges; 2008. Diversity of U.S. Medical Students by Parental Income; vol 8, no 1. https://www.aamc.org/ download/102338/data/aibvol8no1.pdf.

2. Association of American Medical Colleges. Applicants and matriculants data. https://www.aamc.org/download/321474/data/ factstablea9.pdf. Accessed May 29, 2018.

3. Shen MJ, Peterson EB, Costas-Muñiz R, et al. The effects of race and racial concordance on patient-physician communication. a sys tematic review of the literature. J Racial Ethn Heal Disparities. 2018; 5(1):117-140.

4. Walker KO, Moreno G, Grumbach K. The association among specialty, race, ethnicity, and practice location among California physicians in diverse specialties. J Natl Med Assoc. 2012;104(1-2):46-52.

5. Council on Graduate Medical Education. Twentieth report: advancing primary care. https://www.hrsa.gov/advisorycommittees/ bhpradvisory/cogme/Reports/twentiethreport.pdf. Published Dec, 2010.

6. American Academy of Family Physicians. 2018 match results for family medicine. https://www.aafp.org/medical-school-residency/ program-directors/nrmp.html. Published 2018. Accessed May 29, 2018.

7. MacDowell M, Glasser M, Fitts M, Nielsen K, Hunsaker M. A national view of rural health workforce issues in the USA. Rural Remote Health. 2010;10(3):1531.

8. Rosenblatt RA, Andrilla CH, Curtin T, Hart LG. Shortages of medical personnel at community health centers: implications for planned expansion. JAMA. 2006;295(9):1042-1049.

9. Talamantes E. Community college pathways to medical school and family medicine residency training. Ann Fam Med. 2018;16(4):302-307.

10. Bragg DD. Community college access, mission, and outcomes: considering intriguing intersections and challenges. Peabody J Educ. 2001;76(1):93-116.

11. Talamantes E, Mangione CM, Gonzalez K, Jimenez A, Gonzalez F, Moreno G. Community college pathways: improving the U.S. physician workforce pipeline. Acad Med. 2014;89(12):1649-1656.

\section{CORRECTIONS}

Ann Fam Med 2018;16:289. https://doi.org/10.1370/afm.2281.

There is an error in the abstract for: Weidner AKH, Phillips RL, Fang B, Peterson LE. Burnout and scope of practice in new family physicians. Ann Fam Med. 2018;16(3):200-205. The 2nd sentence of the Results section of the Abstract begins, "In bivariate analysis, elements of scope of practice associated with higher burnout... ."

The correct sentence should read, "In bivariate analysis, elements of scope of practice associated with lower burnout rates included providing more procedures/clinical content areas (mean procedures/clinical areas: 7.49 vs $7.02 ; P=.02)$ and working in more settings than the principal practice site $(1+$ additional settings: $57.6 \%$ vs $48.4 \%: P=.001)$; specifically in the hospital $(31.4 \%$ vs $24.2 \% ; P=.002)$ and patient homes (3.3\% vs $1.5 \% ; P=.02)$." The authors regret the error.

Ann Fam Med 2018;16:289. https://doi.org/10.1370/afm.2282.

There was a typo in the print version of Barba C, Hammond S, Hammond RS. The patient profile: improving treatment adherence. Ann Fam Med. 2018;16(3):271.

In the 3rd paragraph of the Learning section, the print version says, "Data also showed that most of our patients with hemoglobin $A_{1 c} \geq$ have intermediate health literacy levels." The value should have been $\geq 9$ and is correct in the online version of the journal available at http://www. AnnFamMed.org/content/16/3/271/. The Annals regrets the error. 